\title{
ĐỀ ÁN NGOẠI NGŨ̉ QUỐC GIA 2020 CÓ THỂ HỌC ĐƯợC GÌ TỪ KINH NGHIẸM CHÂU Á?
}

\author{
Lê Văn Canh ${ }^{1, *}$, Nguyễn Thị Ngọc ${ }^{2}$ \\ ${ }^{1}$ Trung tâm Nghiên cứu giáo dục ngoại ngũ và Đảm bảo chất lương, \\ Truòng Đại học Ngoại ngũ, ĐHQGHN, Phạm Văn Đồng, Cầu Giấy, Hà Nội, Việt Nam \\ ${ }^{2}$ Truờng Cao đẳng Su phạm Nghệ An, Lê Viết Thuật, Vinh, Nghệ An, Việt Nam \\ Nhận bài ngày 03 tháng 01 năm 2017 \\ Chỉnh sửa ngày 18 tháng 7 năm 2017; Chấp nhận đăng ngày 26 tháng 7 năm 2017
}

Tóm tắt: Đề án Ngoại ngữ Quốc gia 2020 đến nay đã bước sang năm thứ 6 (2011-2017) và trong quãng thời gian đó Đề án đã gây ra nhiều tranh luận và nghi ngờ về tính khả thi đối với các mục tiêu đo Đề án đề ra trong cả giới chuyên môn trong và ngoài nước cũng như dư luận xã hội. Với mục đích giúp Bộ Giáo dục và Đào tạo có những điều chỉnh kịp thời trong thời gian còn lại của Đề án, bài viết này phân tích kinh nghiệm thực hiện đổi mới dạy, học, và đánh giá năng lực tiếng Anh của một số nước châu Á trong những năm gần đây. Trên cơ sở kết quả của sự phân tích đó, bài viết đưa ra những khuyến nghị cho việc triển khai Đề án Ngoại ngữ Quốc gia của Việt Nam trong những năm còn lại.

Tù khoá: Đề án Ngoại ngữ Quốc gia 2020, kinh nghiệm, châu Á

\section{Đặt vấn đề}

Với mục tiêu "Đổi mới toàn diện việc dạy và học ngoại ngữ trong hệ thống giáo dục quốc dân, triển khai chương trình dạy và học ngoại ngữ mới ở các cấp học, trình độ đào tạo" để "biến ngoại ngữ trở thành thế mạnh của người dân Việt Nam, phục vụ sự nghiệp công nghiệp hoá, hiện đại hoá đất nước" (Thủ tướng Chính phủ, 2008), Đề án Ngoại ngữ Quốc gia 2020 ra đời. Có thể nói, đây là một dấu mốc quan trọng trong lịch sử giáo dục ngoại ngữ của Việt Nam. Đáng tiếc là khi triển khai, Đề án được xây dựng một cách vội vàng dựa vào kinh nghiệm chủ quan của các cá nhân được giao nhiệm vụ xây dựng Đề án nên những mục tiêu đặt ra vừa phi thực tế vừa thiếu cơ sở khoa học. Đến nay đã bước sang năm thứ 6 (2011-2017) và trong quãng thời gian đó, Đề án đã gây ra nhiều tranh luận và nghi ngờ về tính khả thi đối với các mục tiêu do Đề án đề

\footnotetext{
* Tác giả liên hệ. ĐT.: 84-913563126

Email: levancanhvnu@gmail.com
}

ra trong cả giới chuyên môn trong và ngoài nước cũng như dư luận xã hội. Trong phiên trả lời chất vấn các đại biểu Quốc hội mới đây, Bộ trưởng Bộ Giáo dục và Đào tạo đã phải thừa nhận Đề án không thể đạt được mục tiêu đề ra.

Thất bại của Đề án là điều được báo trước bởi nó dựa trên một cơ sở lý luận nửa vời về giáo dục ngoại ngữ. Cách triển khai lại càng tùy tiện từ mục tiêu, phương pháp đến cách thực hiện. Đó là việc đầu tư tràn lan, đánh đồng tất cả địa phương như nhau, chiến lược bồi dưỡng giáo viên không hiệu quả, mục tiêu $\mathrm{xa}$ vời và hoang tưởng.

Với nỗ lực và quyết tâm thực hiện bằng được những mục tiêu của Đề án trong những năm còn lại, Bộ Giáo dục và Đào tạo đã đề ra một số nhiệm vụ trọng tâm như:

- Tăng cường công tác bồi dưỡng thường xuyên cho đội ngũ giáo viên, giảng viên ngoại ngũ;

- Xây dựng, ban hành chương trình dạy và học ngoại ngữ thống nhất trên toàn quốc, làm cơ sở để phát triển sách giáo khoa, giáo trình; 
- Thực hiện các hoạt động kiểm tra đánh giá, tăng cường ứng dụng công nghệ thông tin trong dạy và học ngoại ngữ; xây dựng hệ thống kiểm tra, đánh giá trong dạy và học ngoại ngữ của Việt Nam theo hướng hội nhập với chuẩn quốc tế, dựa vào nguồn lực chuyên môn trong nước và phối hợp với các chuyên gia, tổ chức tư vấn quốc tế; xây dựng trung tâm khảo thí ngoại ngữ độc lập cấp quốc gia để bảo đảm sự minh bạch, chính xác và thống nhất trong hoạt động khảo thí ngoại ngữ trên cả nước;

- Tăng cường cơ sở vật chất, thiết bị, ứng dụng công nghệ thông tin phục vụ việc dạy và học ngoại ngữ; tăng cường sử dụng các giải pháp công nghệ, các phương tiện phát thanh, truyền hình để hỗ trợ tất cả đối tượng người học có thể tiếp cận bình đẳng với ngoại ngữ, có thể học mọi nơi mọi lúc và đạt được năng lực sử dụng ngoại ngữ.

- Xây dựng môi trường thuận lợi như các phong trào sinh viên tình nguyện dạy ngoại ngữ, câu lạc bộ ngoại ngữ, cộng đồng học tập ngoại ngữ... Tăng cường hợp tác quốc tế trong dạy và học ngoại ngữ như khuyến khích các cơ sở giáo dục mở rộng, đa dạng hóa các hình thức hợp tác quốc tế với các tổ chức ở các quốc gia bản ngữ hoặc có ngôn ngữ quốc gia phù hợp với việc dạy và học ngoại ngữ ở Việt Nam...

(Báo Mới ngày 7/5/2017, http://www. baomoi.com/de-an-ngoai-ngu-9-300-tikhong-ve-dich/c/22208968.epi)

Những mục tiêu nêu trên vẫn chung chung dựa trên ý chí chủ quan của những người có trách nhiệm và đã được đề ra ngay từ khi Đề án bắt đầu vào năm 2011. Với những mục tiêu như thế này thì khi Đề án kết thúc, thực trạng và chất lượng dạy và học ngoại ngữ chắc chắn vẫn không có những thay đổi có ý nghĩa. Bài viết này phân tích kinh nghiệm thực hiện đổi mới dạy, học, và đánh giá năng lực tiếng Anh của một số nước châu Á trong những năm gần đây với hy vọng giúp các nhà quản lý tránh được những sai lầm mà các nước khác đã mắc phải và học tập được những kinh nghiệm hay của họ. Một thực tế đáng buồn là ngành giáo dục và đào tạo Việt Nam chưa bao giờ quan tâm đến việc sử dụng những kết quả nghiên cứu khoa học trong và ngoài nước làm cơ sở cho việc đề ra những đổi mới giáo dục. Hệ quả là hầu hết nếu không muốn nói là tất cả những đề án đổi mới giáo dục ở mọi quy mô của Bộ Giáo dục và Đào tạo đều thất bại và để lại những di chứng nặng nề cho người học, người dạy và xã hội nói chung.

\section{Đổi mới dạy, học và đánh giá năng lực tiếng Anh ở các nước châu Á}

Tiếng Anh ngày càng được đề cao ở nhiều nước châu Á nói chung và Đông Nam Á nói riêng. Thế nhưng ở hầu hết các nước châu Á, năng lực sử dụng tiếng Anh của học sinh sau trung học phổ thông đều rất thấp so với mong đợi. Ví dụ, ở Nhật Bản, năm 2015 người ta tiến hành đánh giá năng lực sử dụng tiếng Anh của học sinh thuộc 480 trường trung học công được chọn ngẫu nhiên. Kết quả cho thấy $29.2 \%$ học sinh đạt điểm 0.0 về kỹ năng viết và $13.3 \%$ (trong số $20.0 \%$ học sinh tham gia thí nói) đạt điểm 0.0 về kỹ năng nói (The Japan Times, 28/03/2015). Vì vậy các quốc gia như Bangladesh, Hàn Quốc, Indonesia, Malaysia, Nhật Bản, Thái Lan và Việt Nam đều chịu áp lực nâng cao khả năng sử dụng tiếng Anh cho công dân của họ (Nunan, 2003; Wedell, 2008). Ví dụ Bộ trưởng Bộ Giáo dục Malaysia gần đây tuyên bố "chính phủ hướng tới mục tiêu xây dựng một chương trình chất lượng cao đưa người Malaysia trở thành những người giỏi tiếng Anh nhất khu vực bằng cách tập trung đầu tư vào nhiều phương diện. Việc này bao gồm nâng cao năng lực sử dụng ngôn ngữ này của học sinh, năng lực giảng dạy, tinh giản chương trình tiếng Anh và đánh giá theo chuẩn quốc tế và cải tiến học liệu." (The Sundaily, 30 August 2016). 
Rất nhiều nước ở châu lục này đã đưa tiếng Anh vào chương trình giáo dục từ bậc tiểu học (Baldauf, Kaplan, Kamwangamalu \& Bryant, 2011; Nunan, 2003) hoặc sử dụng tiếng Anh làm ngôn ngữ giảng dạy một số môn khoa học ở bậc đại học (Kirkpatrick, 2012), sử dụng Khung tham chiếu ngôn ngữ châu Âu (Khung CEFR) để xây dựng chương trình và đánh giá năng lực tiếng Anh của giáo viên và học sinh (Read, 2014).

\section{Đổi mới chương trình và phương pháp giảng dạy}

Nunan (2003) khảo sát tình hình của các nước khu vực Châu Á-Thái Bình Dương (trong đó có Việt Nam) và nhận xét rằng:

Hầu hết những nhà chuyên môn trong lĩnh vực giảng dạy tiếng Anh như một ngôn ngữ thứ hai (TESOL) đều thừa nhận hiệu ứng diễn ra hàng ngày của hiện tượng chính trị-xã hội liên quan đến tiếng Anh như một ngôn ngữ toàn cầu đối với những chính sách mà họ phải thực thi. Có nhiều bằng chứng cho thấy chính phủ các nước trên toàn thế giới đang đưa tiếng Anh trở thành môn học bắt buộc đối với người học ở độ tuổi ngày càng trẻ hơn. [...] Những người làm việc trong các lĩnh vực kinh doanh, công nghiệp và các cơ quan công quyền đều được yêu cầu phải có khả năng giao tiếp bằng tiếng Anh thành thạo. [...] Những yêu cầu về năng lực sử dụng tiếng Anh một mặt tạo cơ hội cho lĩnh vực giảng dạy tiếng Anh nhưng mặt khác chúng đã đặt ra nhiều thách thức cho những người làm nghề giảng dạy tiếng Anh trên phạm vi thế giới (tr. 591).

Một trong những trọng tâm đổi mới dạy và học tiếng Anh ở các nước là đổi mới chương trình, lấy việc áp dụng các phương pháp giảng dạy theo đường hướng giao tiếp. Tuy nhiên, cho đến nay chưa có một quốc gia nào áp dụng thành công các phương pháp giảng dạy này. Nunan (2003) chỉ ra khoảng cách giữa chủ trương đổi mới phương pháp với thực tế giảng dạy là rất lớn (xem Bảng 1).

Bảng 1. Khoảng cách giữa chủ trương đổi mới phương pháp giảng dạy với thực tế giảng dạy trong lớp (theo Nunan, 2003)

\begin{tabular}{|c|c|c|}
\hline $\begin{array}{l}\text { Quốc gia/ vùng } \\
\text { lãnh thổ }\end{array}$ & $\begin{array}{l}\text { Yêu cầu của chương trình } \\
\text { đối với giáo viên }\end{array}$ & Thực tế diễn ra trong lớp học \\
\hline Nhật Bản & \begin{tabular}{|c|} 
Áp dụng các hoạt động giao tiếp để \\
giúp người học trao đồi tình cảm và \\
suy nghĩ cá nhân
\end{tabular} & $\begin{array}{l}\text { Giáo viên coi trọng việc phát triển kỹ năng đọc } \\
\text { và viết để giúp người học vượt qua kỳ thi trung } \\
\text { học phổ thông và vào đại học }\end{array}$ \\
\hline Hàn Quốc & $\begin{array}{l}\text { Áp dụng chương trình giao tiếp-ngữ } \\
\text { pháp-chức năng; chủ trương dạy } \\
\text { tiếng Anh bằng tiếng Anh }\end{array}$ & $\begin{array}{c}\text { Giáo viên không đủ trình độ sử dụng tiếng Anh } \\
\text { nên không đủ tự tin để dạy tiếng Anh bằng tiếng } \\
\text { Anh }\end{array}$ \\
\hline Malaysia & $\begin{array}{l}\begin{array}{c}\text { Áp dụng đường hướng dạy học dựa } \\
\text { trên các hoạt động có kêt quả cụ thể } \\
\text { (task-based) }\end{array} \\
\end{array}$ & $\begin{array}{l}\text { Giáo viên chủ yếu sử dụng các phương pháp } \\
\text { dạy học truyền thống; số đông giáo viên không } \\
\text { đủ tự tin để dạy tiếng Anh bằng tiếng Anh }\end{array}$ \\
\hline Việt Nam & $\begin{array}{l}\text { Đường hướng giao tiếp được ghi } \\
\text { trong chương trình }\end{array}$ & $\begin{array}{l}\text { Sách giáo khoa chủ yếu là các bài tập ngữ pháp } \\
\text { và đọc hiểu. Người học ít có cơ hội sử dụng } \\
\text { tiếng Anh để giao tiếp. }\end{array}$ \\
\hline Đài Loan & $\begin{array}{l}\text { Phát triển kỹ năng giao tiếp cơ bản } \\
\text { bằng tiếng Anh cho người học, tạo } \\
\text { môi trường học tiếng Anh tự nhiên } \\
\text { và thoải mái. }\end{array}$ & $\begin{array}{l}\text { Giáo viên gặp nhiều khó khăn về kỹ năng sử } \\
\text { dụng tiếng Anh và kỹ năng giảng dạy }\end{array}$ \\
\hline Hồng Kông & $\begin{array}{c}\text { Áp dụng các phương pháp dạy học } \\
\text { dựa trên các hoạt động có kêt quả } \\
\text { cụ thể, giao tiếp và theo nhu cầu của } \\
\text { người học (learner-centred). } \\
\end{array}$ & $\begin{array}{l}\text { Trình độ sử dụng tiếng Anh của giáo viên thấp } \\
\text { không đáp ứng được yêu cầu đổi mới; thiếu } \\
\text { giáo viên giỏi. }\end{array}$ \\
\hline Trung Quốc & $\begin{array}{c}\text { Lấy khả năng sử dụng tiếng Anh } \\
\text { thực hiện các chức năng giao tiếp } \\
\text { làm trọng tâm, đáp ứng nhu cầu của } \\
\text { người học }\end{array}$ & $\begin{array}{l}\text { Phương pháp dạy học truyền thống phổ biến; } \\
\text { giáo viên chủ yếu dạy theo sách giáo khoa, coi } \\
\text { trọng ngữ pháp, đọc hiểu và viết theo yêu cầu } \\
\text { của các kỳ thi quan trọng. }\end{array}$ \\
\hline
\end{tabular}


Vì sao lại có khoảng cách giữa chủ trương và thực tế như vậy ở tất cả các quốc gia? Sau đây là những lý do chính. Một là những khó khăn mang tính khái niệm (conceptual) (ví dụ mâu thuẫn với những giá trị truyền thống hay cách hiểu chưa đúng về các phương pháp dạy học giao tiếp. Hai là những điều kiện đặc trưng của lớp học châu Á (các yếu tố liên quan đến học sinh, giáo viên, cách quản lý lớp học và nguồn lực hiện có). Ba là, những khó khăn thuộc về thể chế (như chương trình học hay hệ thống thi cử). Cho đến nay chưa hề có một nghiên cứu nào được công bố về việc áp dụng thành công các phương pháp giảng dạy tiếng Anh giao tiếp được đề xướng ở các nước phương Tây vào điều kiện cụ thể của từng quốc gia và từng cơ sở giáo dục (Butler, 2011). Một vấn đề quan trọng khác là mặc dù năng lực giao tiếp bằng tiếng Anh là mục tiêu cao nhất của mọi chương trình dạy và học tiếng Anh và điều này không có gì phải bàn cãi nhưng năng lực giao tiếp là khái niệm mang tính động và gắn với từng hoàn cảnh giao tiếp cụ thể. Nếu cứ dạy và học vì mục tiêu năng lực giao tiếp chung chung (general communicative competence) thì không thể đạt academic language proficiency). Trong điều kiện thật lý tưởng với tất cả các yếu tố về người học, người dạy, môi trường giáo dục, v.v. nếu mục tiêu học là đạt năng lực giao tiếp ở mức cơ bản thì cần thời gian từ 2-3 năm học liên tục. Nếu mục tiêu là sử dụng tiếng Anh vào các mục đích học thuật (academic), thì cần phải học tích cực trong thời gian từ 5-7 năm.

\section{Đưa tiếng Anh vào chương trình tiểu học}

Hầu hết các quốc gia châu Á trong những năm gần đây đã đưa tiếng Anh vào chương trình giáo dục tiểu học như một môn học bắt buộc. Thậm chí ở Brunei, Malaysia và Philippines, các môn như Toán và Khoa học được dạy bằng tiếng Anh từ lớp 1 (Kirkpatrick, 2011 , tr. 100) còn ở Singapore tiếng Anh là ngôn ngữ giảng dạy tất cả các môn học. Baldauf, Kaplan, Kamwangamalu và Bryant (2011) tóm tắt thực trạng dạy tiếng Anh ở bậc tiểu học tại một số nước châu Á trong bảng 2 dưới đây:

Bảng 2. Thực trạng dạy tiếng Anh ở bậc tiểu học tại một số nước châu Á

\begin{tabular}{ccc}
\hline Quốc gia & Tuổi bắt đầu học tiếng Anh chính thức & Số tiết/tuần \\
\hline Bangladesh & Lớp 1 (6 tuổi) & 5 (tổng 3 giờ/tuần) \\
Trung Quốc & Lớp 3 (8-9 tuổi) & 4 (tổng 80 phút/tuần) \\
Nhật Bản & Lớp 5, 6 & 1 (tổng 45 phút/tuần) \\
Malaysia & Lớp 1 (7 tuổi) & 300 phút/tuần \\
Nepal & Lớp 1 (6 tuổi) & 150 tiết/ năm học \\
Đài Loan (Trung & Luốc) & 2 (tổng 80 phút/tuần) \\
Việt Nam & Lớp 3 ( $9-10$ tuổi) & 3 (tổng 135 phút/tuần) \\
\hline \hline
\end{tabular}

được vì mục tiêu không rõ ràng. Cummins (2008) phân tích hai khái niệm rất quan trọng về cả ý nghĩa lý thuyết và thực tế là 'kỹ năng giao tiếp liên nhân cơ bản' (basic interpersonal communicative skills) và năng lực 'ngôn ngữ mang tính học thuật tri nhận’ (cognitive
Những thách thức chung của tất cả các nước trên là không đủ giáo viên dạy tiếng Anh ở bậc tiểu học trừ Bangladesh và Nepal. Tuy nhiên, nhiều giáo viên tiếng Anh dạy ở tiểu học không được đào tạo bài bản và năng lực sử dụng tiếng Anh thấp (Hamid, 2010; Phyak, 
2011), dẫn đến việc phải thuê giáo viên hợp đồng hoặc giáo viên bản ngữ chưa qua đào tạo (Ali, Hamid \& Moni, 2011, Chen, 2011; Hashimoto, 2011). Nguồn lực hạn hẹp dẫn đến việc phải dựa vào tài trợ của nước ngoài như Bangladesh (Hamid, 2010) hoặc kinh phí đóng góp của phụ huynh như ở Đài Loan (Chen, 2011).

Hàn Quốc là một trong những quốc gia châu Á chi phí nhiều nhất cho việc dạy tiếng Anh cho trẻ em. Khoảng $70 \%$ gia đình ở thủ đô Seoul gửi con đến các cơ sở giáo dục tư nhân để học tiếng Anh (Han, 2010 trích trong Humphries, 2011). Trung bình một năm người Hàn chi 5 tỷ đô la Mỹ (tương đương $20 \%$ ngân sách giáo dục quốc gia) để gửi con đi học tiếng Anh ở nước ngoài (Jeon, 2009). Điều này không những gây ra những thất thoát lớn về tài chính mà còn tạo ra những căng thẳng xã hội và sự phân hóa giữa thành thị và nông thôn (Piller \& Cho, 2013). Tuy nhiên, khả năng sử dụng tiếng Anh của thế hệ trẻ Hàn Quốc vẫn là một quan tâm lớn (Garton, 2014).

\section{Giảng dạy các môn khoa học bằng tiếng Anh (EMI)}

Giảng dạy các môn khoa học bằng tiếng Anh là một trong những xu hướng đang nổi lên ở châu Á (Nunan, 2003) không những ở các quốc gia vốn là thuộc địa cũ của Anh như Ân Độ, Singapore, Malaysia, Hồng Kong (Altbach, 2004) mà còn ở các quốc gia khác như Trung Quốc, Nhật Bản và Hàn Quốc. Shohamy (2013) gọi hiện tượng này là một đại dịch (pandemic) đang lan rộng ở châu Á.

Evans và Morrison (2011) tìm hiểu những khó khăn của sinh viên năm thứ nhất tham gia chương trình học bằng tiếng Anh tại một đại học của Hồng Kông cho thấy sinh viên gặp phải bốn khó khăn lớn: (i) khó hiểu các thuật ngữ chuyên môn; (ii) khó tiếp thu nội dung bài giảng; (iii) không có phương pháp và kỹ năng học phù hợp; và (iv) không đáp ứng được yêu cầu của môn học và của nhà trường. Tại Hàn
Quốc mặc dù chỉ một số môn trong chương trình đào tạo đại học được giảng dạy bằng tiếng Anh, nhưng kết quả cho thấy ở những môn học được dạy bằng tiếng Anh hầu như không có sự trao đổi giữa giảng viên và sinh viên (Kang, Suh, Shin, S-K. Lee, H-J. Lee, \& Choi, 2007), sinh viên không được giảng viên sửa các lỗi về ngôn ngữ (Kang \& Park, 2004). Sinh viên thấy khó hiểu nội dung môn học do kỹ năng nghe hiểu và nói tiếng Anh của họ kém (Kim, 2007). Mặc dù giảng viên được tuyển chọn là những người đã có bằng Tiến sĩ tại các nước nói tiếng Anh chủ yếu là Hoa Kỳ và sinh viên đã được học tiếng Anh 10 năm ở bậc phổ thông, nhưng khi học các môn được giảng dạy bằng tiếng Anh ở đại học sinh viên vẫn không có khả năng hiểu, nói và viết tiếng Anh theo yêu cầu. Vì vậy, việc giảng dạy các môn khoa học bằng tiếng Anh không những không giúp học sinh nâng cao năng lực sử dụng tiếng Anh mà còn tác động tiêu cực đến chất lượng học bộ môn (Byun, Chu, Kim, Park, Kim, \& Jung, 2011).

Malaysia chủ trương dạy các môn khoa học bằng tiếng Anh ở bậc phổ thông từ năm 2004 và chủ trương này đã gây ra những ý kiến trái chiều trong xã hội, đặc biệt chủ trương này đã tạo ra sự bất bình đẳng trong xã hội giữa số ít con em nhà giàu gốc Hoa và một ít người Ma-lay được học bằng tiếng Anh với đa số con em gia đình kinh tế khó khăn (Omar, 2012).Vì vậy, chủ trương giảng dạy các môn toán và khoa học bằng tiếng Anh ở Malaysia luôn thay đổi theo thời tiết chính trị của quốc gia này.

Philippines vốn là thuộc địa cũ của Hoa Kỳ, nhưng việc sử dụng tiếng Anh để dạy các môn toán và khoa học đã gây ra không ít áp lực và sự bất bình đẳng cho học sinh cho nên gần đây Chính phủ Philippines phải thay đổi chính sách này theo đó, tiếng Anh chỉ được sử dụng để dạy các môn toán và khoa học từ lớp 3 (Walker \& Decker, 2008). 
Ở Nhật Bản, Kế hoạch hành động 2003 nhằm nâng cao khả năng sử dụng tiếng Anh cho học sinh người Nhật và với chủ trương tư nhân hóa toàn bộ các trường đại học, số lượng trường đại học sử dụng tiếng Anh để giảng dạy các môn khoa học ngày càng tăng chủ yếu để đáp ứng yêu cầu do số lượng sinh viên quốc tế tăng lên. Hiện tại có khoảng $25 \%$ số trường đại học của Nhật Bản tiến hành giảng dạy một số môn bằng tiếng Anh, tuy nhiên số sinh viên theo học các môn học giảng dạy bằng tiếng Anh là rất ít (Brown, 2014). Với Đề án Global 30, Nhật Bản dự định sẽ thu hút khoảng 300.000 sinh viên nước ngoài đến học tại các trường của Nhật Bản vào năm 2020. Để hiện thực hóa mục tiêu này, Nhật Bản đề ra chủ trương "chỉ dạy bằng tiếng Anh" (English only) chứ không sử dụng thuật ngữ thông thường là "Tiếng Anh là phương tiện giảng dạy - EMI) (Hashimoto, 2013). Nghiên cứu của Taguchi \& Naganuma (2006) cho thấy học sinh gặp rất nhiều trở ngại trong việc nghe giảng bằng tiếng Anh.

Năm 2001, Bộ Giáo dục Trung Quốc chỉ thị cho các trường đại học sử dụng tiếng Anh làm ngôn ngữ giảng dạy cho các môn học như công nghệ thông tin, công nghệ sinh học, công nghệ vật liệu mới, tài chính, thương mại quốc tế, kinh tế và luật (Nunan, 2003). Đồng thời khoảng 10 trường đại học nổi tiếng nhất của Trung Quốc quyết định mua toàn bộ chương trình và tài liệu giảng dạy của Đại học Harvard, Stanford và MIT. Các nghiên cứu của Lei và $\mathrm{Hu}$ (2014), Hu và Li (2017) về hiệu quả giảng dạy các môn khoa học bằng tiếng Anh ở các trường đại học trọng điểm của Trung Quốc cho thấy các chương trình này không có hiệu quả gì đối với việc phát triển năng lực sử dụng tiếng Anh của học sinh.

\section{Năng lực sử dụng tiếng Anh của giáo viên (Teachers' English proficiency)}

Năng lực sử dụng tiếng Anh kém là vấn đề chung ở mọi quốc gia châu Á (Butler, 2004;
Baker, 2008; Littlewood, 2007; Nunan, 2003) mặc dù cho đến nay chưa có kết luận khoa học dứt khoát giáo viên tiếng Anh ở từng cấp học cần đạt năng lực sử dụng tiếng Anh ở cấp độ nào. Butler (2004) khảo sát năng lực sử dụng tiếng Anh của giáo viên tiếng Anh bậc tiểu học tại Hàn Quốc, Đài Loan và Nhật Bản. Kết quả giáo viên trả lời phiếu hỏi (questionnaire) cho thấy đại đa số giáo viên chưa được đào tạo đầy đủ và năng lực sử dụng tiếng Anh của họ là một trong những vấn đề đáng lo ngại. Giáo viên thừa nhận năng lực sử dụng tiếng Anh của họ chưa đáp ứng được yêu cầu của giảng dạy nhất là ở kỹ năng nói và viết và kiến thức ngữ pháp khẩu ngữ.

Theo báo cáo của Bộ Giáo dục Malaysia, trong số 40.000 giáo viên tiếng Anh của quốc gia này có $52.0 \%$ đạt trình độ $\mathrm{C} 1$ theo Khung CEFR, số còn lại (48.0\%) đạt trình độ $\mathrm{B} 2$. Đề án cải cách việc dạy và học tiếng Anh 2015-2025 của Malaysia (gọi là The Malaysia Education Blueprint 2013-2025) đặt ra mục tiêu người Malaysia phải là những người sử dụng tiếng Anh tốt nhất trong khu vực, Malaysia đang có kế hoạch nhờ nước Anh (Cambridge English) giúp bồi dưỡng giáo viên để phấn đấu đạt $100 \%$ giáo viên tiếng Anh đạt trình độ $\mathrm{C} 2$ theo khung $\mathrm{CEFR}$ vào năm 2020 (The Sun Daily, 30/08/2016).

\section{Đánh giá năng lực sử dụng tiếng Anh}

Ít nhất có bốn quốc gia và vùng lãnh thổ sử dụng Khung tham chiếu Châu Âu (CEFR) có điều chỉnh theo yêu cầu riêng để đánh giá năng lực sử dụng tiếng Anh là Đài Loan, Nhật Bản, Trung Quốc và Việt Nam.

Đài Loan sử dụng khung CEFR để công nhận trình độ tương đương giữa các bài thi khác nhau do các cơ sở giáo dục thực hiện nhất là bài thi quốc gia đánh giá năng lực tiếng Anh phổ thông (GEPT) (Wu, 2012). Mức chuẩn tối thiểu được quy định đối với sinh viên tốt nghiệp các chương trình đào tạo sư phạm là tương đương bậc B2 của khung 
CEFR, còn sinh viên tốt nghiệp các trường đại học khác là $\mathrm{B} 1$. Tuy nhiên việc xác định chuẩn tương đương cũng gặp nhiều rắc rối nhất là đối với các bài thi đánh giá năng lực tiếng Anh theo các mục đích khác nhau do Bộ Giáo dục Đài Loan chưa có người đủ trình độ chuyên môn để làm công việc này và việc điều chỉnh khung CEFR để hướng dẫn giảng dạy cho phù hợp với điều kiện văn hóa và xã hội của Đài Loan cũng rất khó khăn (Wu, 2012). Cheung (2012) cho rằng trong điều kiện tiếng Anh là một ngoại ngữ và học sinh Đài Loan không có điều kiện tiếp xúc và sử dụng tiếng Anh trong giao tiếp ngoài xã hội nên không thể thể hiện được kỹ năng sử dụng tiếng Anh theo các đặc tả của khung CEFR. Theo ý kiến của Cheung thì việc điều chỉnh khung CEFR cho phù hợp nhất là để đánh giá năng lực tiếng Anh của học sinh tiểu học đòi hỏi một khối lượng công việc khổng lồ khó có thể thực hiện được.

Tại Nhật Bản, một nhóm các nhà nghiên cứu của trường Đại học Ngoại ngữ Tokyo được giao nhiệm vụ thực hiện đề án điều chỉnh khung CEFR cho phù hợp với điều kiện của Nhật Bản từ năm 2008 đến 2011 và kết quả là họ đưa ra được một khung gọi là CEFR-J, tức Khung tham chiếu châu Âu của Nhật Bản (Negishi \& Tono, 2014). Khung CEFR-J có hai điều chỉnh lớn. Một là họ thêm một bậc gọi là tiền $\mathrm{A} 1$ (Pre-A1) còn bậc $\mathrm{A} 1$ chia làm ba bậc nhỏ là $\mathrm{A} 1.1, \mathrm{~A} 1.2$, và $\mathrm{A} 1.3$ vì họ cho rằng trên $80 \%$ học sinh Nhật Bản sẽ có trình độ nằm trong khoảng bậc $\mathrm{A} 1$ và $\mathrm{A} 2$. Tương tự như vậy bậc từ $\mathrm{A} 2$ đến $\mathrm{B} 2$ cũng được chia thành hai bậc nhỏ. Điều chỉnh thứ hai là điều chỉnh các đặc tả về năng lực sử dụng tiếng Anh trong các bậc của khung CEFR để tính đến những khó khăn của học sinh Nhật Bản khi sử dụng tiếng Anh để giao tiếp. Tất cả giáo viên và học sinh đều được thông tin đầy đủ về những điều chỉnh này.

Trung Quốc cũng sử dụng khung CEFR nhưng không phải để phục vụ mục đích đánh giá mà họ dùng để tham khảo và xây dựng khung riêng của Trung Quốc gọi là CCFR (Common Chinese Framework of Reference for Languages) và dùng khung này để hướng dẫn giảng dạy (Jin và cộng sự, 2014). Tuy nhiên nhóm xây dựng khung này cũng gặp nhiều khó khăn do bản chất của hệ thống giáo dục Trung Quốc và sự phản kháng của những người liên đới. Hiện tại Bộ Giáo dục Trung Quốc giao cho Cục Khảo thí giáo dục quốc gia tiếp tục nghiên cứu và triển khai khung này.

Nhìn chung, ý kiến của các nhà giáo dục là khung CEFR cần phải được điều chỉnh thậm chí cần có một tư duy và cách nhìn mới về khung này để có thể giúp cho việc xác định mục tiêu và chương trình giáo dục sao cho phù hợp với các điều kiện xã hội và giáo dục đa dạng của từng quốc gia (Read, 2014).

Hàn Quốc không lấy khung CEFR làm cơ sở đánh giá năng lực sử dụng tiếng Anh. Họ xây dựng khung đánh giá riêng của họ gọi là Bài thi năng lực tiếng Anh quốc gia (NEAT). Đề án xây dựng bài thi này được triển khai từ năm 2007. Từ năm 2007 đến 2008 nhóm nghiên cứu thực hiện các nghiên cứu sơ bộ và đến năm 2009 thì bài thi được đưa vào thư nghiệm cho đến năm 2012. Theo khung này, năng lực sử dụng tiếng Anh được chia thành ba cấp độ 1,2 , và 3 . Cấp độ 3 là cấp độ cao nhất dùng để tuyển sinh vào các trường đại học có yêu cầu thí sinh phải có kỹ năng tiếng Anh thực hành (Practical English Test). Cấp độ 2 dành cho học sinh tốt nghiệp hệ trung học phổ thông. Kết quả thử nghiệm bài thi mới cho thấy một số hạn chế sau (Lee, 2015, tr. 59-60):

1. Khó khăn trong việc chấm bài theo phương pháp khách quan và tính thực tế của bài thi hạn chế.

2. Khuyến khích việc luyện thi trong các cơ sở luyện thi tư nhân.

3. Các trường phổ thông chưa sã̃n sàng áp dụng bài thi mới.

4. Giáo viên gặp nhiều khó khăn trong việc dạy các kỹ năng ngôn ngữ sản sinh (nói và viết).

5. Giáo viên không phát triển kỹ năng sử dụng tiếng Anh cho học sinh mà chỉ tập trung dạy cho học sinh đi thi. 
6. Những người tham gia chấm thi chưa đủ kiến thức và kỹ năng đánh giá người học.

Có thể thấy việc tìm ra một phương pháp đánh giá năng lực sử dụng tiếng Anh của học sinh phù hợp để khuyến khích đổi mới phương pháp dạy và học của các nước châu Á vẫn đang là một quá trình thử và sai (trial and error). Những giá trị văn hóa, xã hội và giáo dục của các nước châu Á không thích ứng với các phương pháp đánh giá của các nước phương Tây, kể cả khung CEFR.

\section{Kinh nghiệm cho Đề án Ngoại ngữ Quốc gia 2020}

Việc coi trọng vai trò của tiếng Anh trong công cuộc phát triển và hiện đại hóa đất nước đã thúc đẩy nhiều quốc gia châu Á đặt ưu tiên đầu tư vào mục tiêu nâng cao năng lực sử dụng tiếng Anh của công dân nước mình nhằm tạo ra những ưu thế cạnh tranh về khoa học, công nghệ và kinh tế. Tuy nhiên, chưa có một bài học thành công nào được ghi nhận ở hầu hết các quốc gia châu Á và giải pháp nâng cao chất lượng dạy và học tiếng Anh vẫn đang là cái mà các quốc gia này đi tìm. Việc đầu tư không hiệu quả vào mục tiêu nâng cao chất lượng giáo dục tiếng Anh ở châu Á bắt nguồn từ một nguyên nhân cơ bản là các quốc gia này đang tích cực tham gia vào trò chơi của chủ nghĩa tân tự do (neoliberalism) của phương Tây mà không tính đến các đặc điểm về ngôn ngữ học xã hội và văn hóa của mình. Điều này được minh chứng bằng thực tế là tất cả những nỗ lực đổi mới dạy và học tiếng Anh của các chính phủ châu Á đều dựa trên năm quan niệm mang tính huyền thoại của phương Tây về dạy và học tiếng Anh dưới đây:

1. Con đường nâng cao chất lượng dạy và học tiếng Anh hiệu quả nhất là sử dụng tiếng Anh làm phương tiện giảng dạy các môn học khác, trước hết là toán và các môn khoa học;

2. Để có năng lực sử dụng tiếng Anh tốt, cần phải học tiếng Anh càng sớm càng tốt;

3. Quá trình học tiếng Anh như một ngoại ngữ luôn chịu ảnh hưởng tiêu cực của tiếng mẹ đẻ, do vậy cần khuyến khích việc dạy tiếng Anh bằng tiếng Anh trong lớp học.

4. Đường hướng giao tiếp là đường hướng dạy và học ngoại ngữ hiệu quả nhất cho mọi đối tượng người học.

5. Đồng nhất 'kỹ năng giao tiếp liên nhân cơ bản' với 'năng lực ngôn ngữ mang tính học thuật tri nhận' (Cummins, 2008) trong việc đề ra mục tiêu và tiêu chí đánh giá năng lực sử dụng tiếng Anh.

Năm quan niệm không có căn cứ khoa học trên giúp lý giải vì sao các chính phủ châu Á chủ trương tiến hành giảng dạy tiếng Anh càng sớm càng tốt, thực hiện việc dạy các môn toán và khoa học bằng tiếng Anh ngay từ bậc tiểu học bất chấp những kết quả nghiên cứu trong lĩnh vực ngôn ngữ học ứng dụng đã chỉ ra rằng người học cần được học ngoại ngữ ít nhất năm năm trước khi có khả năng lĩnh hội các khái niệm khoa học bằng tiếng Anh (Cummins, 2008). Chủ trương dùng tiếng Anh làm ngôn ngữ giảng dạy các môn khoa học và toán được dựa trên những quan niệm đơn giản và không có căn cứ khoa học (Hu \& Li, 2017). Chủ trương đó chủ yếu là do sức ép xếp hạng quốc tế các trường đại học và thu hút học sinh nước ngoài đến học.

Quan niệm cần học tiếng Anh càng sớm càng tốt cũng cần được xem xét nghiêm túc. Mặc dù đã có một số chương trình dạy tiếng Anh cho học sinh tiểu học thành công, cần phân biệt giữa việc dạy tiếng Anh cho trẻ em ở các trường tư hay các trung tâm tư nhân dồi dào về nguồn lực, trình độ và năng lực của giáo viên tốt, trang thiết bị dạy và học hiện đại với việc dạy tiếng Anh ở các trường tiểu học công lập nơi tất cả các yếu tố đều kém hơn trường tư (Martin, 2005). Ngay cả ở châu Âu, việc dạy ngoại ngữ cho học sinh tiểu học cũng không mang lại kết quả mong muốn. Jackel, Schurig, Florian và Ritter (sắp công bố) báo cáo kết quả nghiên cứu trong nhiều năm trên một nhóm học sinh Đức bắt đầu học tiếng Anh từ lớp năm và nhóm bắt đầu học từ lớp 7 . Kết 
quả cho thấy nhóm bắt đầu học từ lớp 7 vượt xa nhóm bắt đầu học từ lớp 5 về khả năng sủ dụng tiếng Anh.Việc đưa tiếng Anh vào các trường tiểu học cũng ảnh hưởng đến thời gian dành cho trẻ em phát triển các kỹ năng ngôn ngữ bằng tiếng mẹ đẻ. Các học giả quốc tế đã nhiều lần khuyến cáo trẻ em cần được phát triển các kỹ năng ngôn ngữ bằng tiếng mẹ đẻ đầy đủ trước khi bắt đầu học một ngoại ngữ nào đó (Benson, 2008; Haddad, 2008). Đây cũng chính là quan điểm của UNESCO.

Chủ trương 'dạy tiếng Anh bằng tiếng Anh' gần đây đã bị các nghiên cứu về hiện tượng chuyển ngữ (code-switching) trong các lớp học ở châu Á bác bỏ (Braine, 2010; Macaro, 2009; Barnard \& McLellan, 2013). Các nghiên cứu về việc sử dụng tiếng mẹ đẻ trong học ngoại ngữ được tiến hành vào đầu thế kỷ 21 đều khẳng định rằng tiếng mẹ đẻ là nguồn tài nguyên (resources) quý đối với quá trình học ngoại ngũ̃ (Canagarajah, 2011; Creese \& Blackledge, 2010; Garcia \& Li, 2014; Macaro, 2009). Macaro (2014) cho rằng: "vấn đề có nên sử dụng ngôn ngữ thứ nhất trong giao tiếp bằng khẩu ngữ hay trong các học liệu được in ấn cho các lớp học ngôn ngữ thứ hai hay ngoại ngữ hay không có lẽ là vấn đề cơ bản nhất đối với các nhà nghiên cứu thụ đắc ngôn ngữ thứ hai, giáo viên ngoại ngữ và những người làm chính sách trong thập kỷ thứ hai của thế kỷ 21" (tr. 10). Thế kỷ 21 là kỷ nguyên đa ngôn ngữ, đa văn hóa. Do vậy, Việt Nam cũng như các quốc gia châu Á cần nghiên cứu xây dựng mô hình giảng dạy song ngữ linh hoạt (dynamic bilingual model), tránh áp dụng máy móc chủ trương đơn ngữ tức là dạy tiếng Anh bằng tiếng Anh. Giáo viên cần được bồi dưỡng những kỹ năng giúp học sinh biết cách sử dụng tiếng mẹ đẻ một cách hiệu quả cho việc học tiếng Anh như một ngoại ngữ (Canagarajah, 2011; Creese \& Blackledge, 2010).

Ở hầu hết các nước châu Á, các phương pháp dạy ngoại ngữ của châu Âu và Bắc Mỹ được các học giả địa phương và phương Tây nhập khẩu trọn gói với một niềm tin không có căn cứ là cái gì tốt cho phương Tây sẽ tốt cho châu Á và giúp châu Á sánh ngang châu Âu. Đã có nhiều bằng chứng khoa học (Butler, 2011; Canh \& Barnard, 2009; Chow \& MokCheung ,2004; Hiệp, 2007; Hu, 2005 Li, 1998; Littlewood, 2007; Nishino \& Watanabe, 2008; Sato and Kleinsasser, 1999; Wang, 2007) cho thấy rằng hiệu quả của việc bồi dưỡng giáo viên về các phương pháp giảng dạy ngoại ngữ của phương Tây là rất hạn chế do nhiều lý do. Một là, giáo viên không hiểu cơ sở lý luận của phương pháp giảng dạy mới. Hai là, thiếu sự hỗ trợ giáo viên thực hiện phương pháp giảng dạy sau khi được bồi dưỡng. Ba là, phương pháp giảng dạy mới không tạo ra được sự gắn kết với văn hóa học truyền thống của địa phương. Rất tiếc, những kết quả nghiên cứu này không được các nhà làm chính sách ở các nước châu Á tiếp thu.

\section{Kết luận}

Có thể nói trong những năm gần đây, các nước châu Á rất tích cực thúc đẩy việc dạy và học tiếng Anh với rất nhiều chủ trương mới. Đáng tiếc, tất cả đều thất bại kể cả việc áp dụng Khung tham chiếu (CEFR) châu Âu để đổi mới việc xây dựng chương trình và phương pháp đánh giá. Trên thực tế, do giảng dạy tiếng Anh là một ngành kinh doanh đem lại lợi nhuận khổng lồ nên người ta thường công bố những câu chuyện thành công về những phương pháp giảng dạy cải tiến mang lại kết quả học tập của học sinh cao, những giáo viên tận tụy với đổi mới, những chương trình giao tiếp mà ít khi công bố những thất bại, những giáo viên không yêu nghề, những chương trình học làm cho giáo viên và học sinh không rõ trọng tâm hay mục tiêu là gì (Anderson, 2009). Một điều thú vị là các học giả phương Tây luôn tuyên truyền cho các nước châu Á những phương pháp giảng dạy của họ, nhưng chất lượng học ngoại ngữ ở các nước phương Tây cũng 
không hơn gì chất lượng dạy tiếng Anh ở các nước châu Á (Driscoll, Macaro \& Swarbrick, 2014). Do vậy, các nước châu Á nói chung và Việt Nam nói riêng cần phải biết cách tham gia cuộc chơi toàn cầu trong lĩnh vực dạy tiếng Anh bằng minh triết (wisdom) của chính mình. Một minh triết như vậy sẽ khuyến khích các nước châu Á đi tìm cho mình một mô hình đổi mới dạy, học và đánh giá phù hợp với những giá trị truyền thống cũng như điều kiện kinh tế, xã hội của nước mình. Mô hình đó phải bắt đầu từ những nghiên cứu miêu tả thực trạng bằng những phương pháp nghiên cứu và phương pháp báo cáo kết quả phù hợp và khoa học. Không một mô hình nào, không một lý thuyết nào có thể giúp chúng ta hiểu được bản chất của hiện tượng mà không bắt đầu bằng việc miêu tả hiện tượng. Nói cách khác phải tìm ra bản chất của vấn đề rồi mới có thể đưa ra giải pháp mang tính lý thuyết. Mô hình mới đó phải dựa trên những phân tích chính trị vi mô (micropolitics), tức là những yếu tố liên quan đến các bên liên đới và quan hệ giữa họ với nhau trong quá trình cạnh tranh hợp tác với nhau để đạt được mục đích của mình trong một môi trường xã hội cụ thể. Triết lý đó dựa trên câu nói nổi tiếng của Earl Stevick (1980, tr. 4) rằng: "Thành công ít phụ thuộc vào việc phân tích ngôn ngữ, học liệu và phương pháp giảng dạy mà phụ thuộc nhiều vào những gì diễn ra bên trong từng con người và giữa những người hiện diện trong lớp học ngoại ngữ.” Không có đổi mới nào trong giáo dục nói chúng và giáo dục ngoại ngữ nói riêng thành công nếu không quan tâm đến cái đang diễn ra bên trong người dạy và người học và giữa người học với người học, giữa người dạy với người học trong một lớp học cụ thể.

Công việc đó bắt đầu bằng việc đoạn tuyệt với quan niệm nhấn mạnh vào những yếu kém (deficiency view), coi kiến thức và kỹ năng sử dụng tiếng Anh của người dạy và người học là yếu kém để chấp nhận quan điểm phát triển (developmental view) coi kiến thức và kỹ năng đó đang trong quá trình phát triển. Quan điểm phát triển đặt trọng tâm vào việc bồi dưỡng và phát triển động lực vươn tới thành tích (achievement motivation) của người học và người dạy, giúp họ thay đổi bản ngã (identity) mà thiếu yếu tố này thì thành công của việc dạy và học ngoại ngữ sẽ rất hạn chế (Norton, 2017). Việc đặt ra những mục tiêu học tiếng Anh phi thực tế, không dựa trên những chứng cứ khoa học sẽ chỉ mang tính chính trị và lãng phí nguồn lực. Trong môi trường học tiếng Anh như các nước châu Á, do thiếu môi trường ngôn ngữ cần thiết nên người học không có nhu cầu trước mắt phải có kỹ năng sử dụng tiếng Anh nên động lực và sự đầu tư của học không cao. Năng lực sử dụng tiếng Anh của giáo viên không đáp ứng đòi hỏi của việc dạy tiếng Anh theo các phương pháp giảng dạy do các nước phương Tây đề xướng. Cho dù Việt Nam và các nước châu Á khác có đầu tư nâng cao năng lực tiếng Anh của giáo viên khi quay lại trường giảng dạy, năng lực đó sẽ giảm đi rất nhanh do không có môi trường sử dụng tiếng Anh thường xuyên ở trình độ cao. Do vậy, cần đặt ra một trình độ ngưỡng cơ bản (threshold level) để giáo viên phấn đấu chứ không nên đề ra yêu cầu quá cao vì nó vừa không thực tế, vừa gây áp lực không cần thiết cho giáo viên. Đối với việc bồi dưỡng giáo viên, điều quyết định là giúp họ có kiến thức và kỹ năng tổ chức các hoạt động tương tác (interaction) trong lớp học sao cho những hoạt động đó giúp người học sử dụng được tiếng Anh ở trình độ cơ bản một cách tự tin.

Một vấn đề quyết định khác đối với việc dạy và học tiếng Anh ở Việt Nam là coi trọng hơn nữa các hoạt động học tiếng Anh ở ngoài nhà trường hay ở nhà của người học. Muốn vậy, trước tiên phải tạo được động lực và hứng thú cũng như thái độ tích cực của người học đối với tiếng Anh. Đây là một thách thức không nhỏ. Larsen-Freeman (2016) cho rằng: 
Một phần trách nhiệm của chúng ta [giáo viên, cán bộ quản lý] là giúp người học kết nối với môi trường ngôn ngữ ngoài lớp học - giúp họ thích ứng được những thay đổi to lớn đang làm biến đổi thế giới, hoặc ít ra cũng thích ứng được một phần của những biến đổi đó liên quan đến việc sử dụng ngôn ngữ (tr. 7).

Những chủ trương xây dựng cộng đồng học tập ngoại ngữ của Việt Nam là rất vu vơ, hình thức. Những chủ trương áp dụng công nghệ một cách duy ý chí, thiếu những chứng cứ khoa học sẽ chỉ dẫn đến tham nhũng và lãng phí nguồn lực. Nếu chúng ta chưa hiểu cách thức người học học ngoại ngữ ngoài lớp học như thế nào thì những khái niệm như 'áp dụng công nghệ trong dạy và học ngoại ngữ” hay "học kết hợp phương thức truyền thống với học bằng công nghệ (blended learning) sẽ mãi mãi là những khái niệm mang tính đãi bôi. Vấn đề không phải là cố áp dụng công nghệ mới nhất vào dạy và học ngoại ngữ mà câu hỏi cần đặt ra là: "Vấn đề $\mathrm{X}$ cần được giải quyết bằng công nghệ nào?". Nếu không làm như vậy, chúng ta sẽ rơi vào 'hiệu ứng đồ chơi mới'.

Từ những kinh nghiệm của các nước châu Á, Việt Nam cần thay đổi tư duy áp đặt, đề ra những chủ trương và mục tiêu dạy tiếng Anh phi thực tế. Tiếng Anh đã là ngôn ngữ toàn cầu cho nên cần xem lại chủ trương đánh giá năng lực sử dụng ngoại ngữ của người học theo tiêu chí sử dụng tiếng Anh của người bản ngữ. Phát biểu của Bộ trưởng Bộ Giáo dục và Đào tạo: "Dạy và học ngoại ngữ mà không chuẩn thì thà không dạy còn hơn. Vì các em học sai từ nhỏ thì sau này rất khó sửa. Không phải cứ tốt nghiệp đại học sư phạm ngoại ngữ là dạy được ngoại ngũ̃, vì phải chuẩn và có kỹ năng" (Sài Gòn Giải phóng Online ngày 17/9/2016, http://www.sggp.org. vn/day-ngoai-ngu-khong-chuan-tha-khong-daycon-hon-145950.html) cần được bàn lại một cách khoa học. Không có tiếng Anh nào là tiếng Anh chuẩn trên thế giới và ngay cả ở các nước nói tiếng Anh.
Cuối cùng, Việt Nam cần đặt hoạt động học ngoại ngữ vào vị trí trung tâm của đổi mới chứ không phải là hoạt động dạy, hay trình độ ngoại ngữ của giáo viên ở bậc mấy trong Khung năng lực ngoại ngữ quốc gia. Thành công trong việc học tiếng Anh của Phillipines là nhờ phương pháp học chứ không phải chỉ là nhờ phương pháp dạy. Do vậy cần chú trọng cả việc bồi dưỡng cách dạy của giáo viên và cách học của học sinh. Đã đến lúc những cán bộ quản lý giáo dục có liên quan đến giáo dục ngoại ngữ ở Việt Nam phải tự vượt lên chính mình từ bỏ văn hóa 'ra lệnh' hay 'áp đặt', từ bỏ suy nghĩ cho rằng mọi thứ đều có thể đánh giá theo định lượng và 'mọi người đều mặc áo cùng một cỡ'. Đặt ra chuẩn làm mục tiêu phấn đấu là việc cần làm nhưng chuẩn hóa (standardization) mà không tính đến sự khác biệt về điều kiện dạy và học sẽ dẫn đến tai họa.

\section{Tài liệu tham khảo}

\section{Tiếng Việt}

Thủ tướng Chính phủ (2008). Quyết định 1400/QĐ-TTg về việc phê duyệt Đề án "Dạy và học ngoại ngũ trong hệ thống giáo dục quốc dân giai đoạn 2008 - 2020" ngày 30 tháng 9 năm 2008.

\section{Tiếng Anh}

Ali, N. L.,Hamid, M.O., \& Moni, K. (2011). English in primary education in Malaysia: Policies, outcomes and stakeholders' lived experiences. Current Issues in Language Planning, 12(2), 147-166.

Anderson, J. C. (ed.) (2009). The politics of language education: Individuals and institutions. Bristol, UK: Multilingual Matters.

Baker, W. (2008). A critical examination of ELT in Thailand: The role of cultural awareness. RELC Journal, 39(1), 131-146.

Baldauf Jr., R. B., Kaplan, R. B., Kamwangamalu, N., \& Bryant, P. (2011). Success or failure of primary second/foreign language programmes in Asia: What do the data tell us?. Current issues in language planning, 12(2), 309-323.

Barnard, R., \& McLellan, J. (Eds.) (2013). Codeswitching in university English-medium classes: Asian perspectives. Bristol, UK: Multilingual Matters. 
Braine, G. (2010). Nonnative speaker English teachers: Research, pedagogy, and professional growth. New York, NY: Routledge.

Brown, H. (2014). Contextual factors driving the growth of undergraduate English-medium instruction programs at universities in Japan. The Asian Journal of Applied Linguistics, 1(1),50-63.

Butler, Y. G. (2004). What level of English proficiency do elementary school teachers need to attain to teach EFL? Case studies from Korea, Taiwan, and Japan. TESOL Quarterly, 245-278.

Butler, Y. G. (2011). The Implementation of Communicative and Task-Based Language Teaching in the Asia-Pacific Region. Annual Review of Applied Linguistics, 31, 36-57.

Byun, K., Chu, H., Kim, M., Park, I., Kim, S., \& Jung, J. (2011). English-medium teaching in Korean higher education: Policy debates and reality. Higher Education, 62, 431-449.

Canh, L. V., \& Barnard, R. (2009). Curricular innovation behind closed classroom doors: A Vietnamese case study. Prospect, 24, 20-33.

Canagarajah, S. (2011). Codemeshing in academic writing: Identifying teachable strategies of translanguaging. The Modern Language Journal, 95(3), 401-417.

Chen, H. (2011). Parents' perspectives on the effects of primary EFL education policy in Taiwan. Current Issues in Language Planning, 12(2), 205-224.

Cheung, H. (2012). Academic perspectives from Taiwan. In M. Byram \& L. Pamenter (Eds.), The Common European framework of reference: The globalization of language education policy (pp. 224230). Bristol, UK: Multilingual Matters.

Chow, A. \& Mok-Cheung, A. (2004). English language teaching in Hong Kong SAR: Tradition, transition and transformation. In W.K. Ho \& R. Y.L. Wong (Eds.), English language teaching in East Asia today (pp. 150-177). Singapore: Eastern Universities Press.

Creese, A., \& Blackledge, A. (2010). Translanguaging in the bilingual classroom: A pedagogy for learning and teaching? The modern language journal, 94(1), 103-115.

Cummins, J. (2008). BIGS and CALP: Empirical and theoretical status of the distinction. In B. Street \& N. H. Hornberger (eds.), Encyclopedia of language and education (2 ${ }^{\text {nd }}$ ed.), Vol.2: Literacy (pp. 71-83). New York: Springer Science \& Business Media LLC.

Driscoll, P., Macaro, E., \& Swarbrick, A. (eds.).(2014). Debates in modern languages education. London: Routledge.
Evans, S., \& Morrison, B. (2011). Meeting the challenges of English-medium higher education: The first-year experience in Hong Kong. English for Specific Purposes, 30, 198-208.

Garton, S. (2014). Unresolved issues and new challenges in teaching English to young learners: The case of South Korea. Current Issues in Language Planning, 15(2), 201-219.

Hamid, O. (2010). Globalization, English for everyone and English teacher capacity: Language policy discourses and realities in Bangladesh. Current Issues in Language Planning, 11(4), 289-310).

Hashimoto, K. (2011). Compulsory 'foreign language activities' in Japanese primary schools. Current Issues in Language Planning, 12(2), 167-184.

Hashimoto, K. (2013). 'English-only', but not a medium-of-instruction policy: The Japanese way of internationalizing education both for domestic and overseas students. Current Issues in Language Planning, 14(1), 16-33.

Hiep, P. H. (2007). Communicative language teaching: Unity within diversity. ELT Journal, 61 (3), 193-201.

Hu, G. (2005). 'CLT is best for China' - An untenable absolutist claim. ELT Journal, 59 (1), 65-68.

Hu, G., \& Li, X. (2017). Asking and answering questions in English-medium instruction classrooms: What is the cognitive and syntactic complexity level? In Zhao, J. \& Quentin, L (Ed.), English-medium instruction in Chinese universities (pp. 184-203). Singapore: National Institute of Education.

Humphries, S. (2011). Exploring the impact of the introduction of new EFL textbooks on teachers' practices and attitudes at a technical college in Japan (Unpublished $\mathrm{PhD}$ thesis). Macquarie University, North Ryde, NSW.

Jackel, N., Schurig, M., Florian, M., \& Ritter, M. (in print). From early starters to late finishers? A longitudinal study of early foreign language learning in schools. Language Learning.

Jeon, M. (2009). Globalization and native English speakers in English programmes in Korea (EPIK). Language, Culture and Curriculum, 22(3), 231-243.

Jin, Y., Wu, Z., Anderson, C.,\& Song, W. (2014). Developing the Common Chinese framework of reference for languages: Challenges at macro and micropolitical levels. Paper presented at the Language Testing Research Colloquium, Amsterdam, the Netherlands, June 4-6.

Kang, S-Y., Park, H-S. (2004). Student beliefs and attitudes about English medium instruction: Report of questionnaire study. Yonsei Review of Educational Research, 17(1), 33-53. 
Kim, M-J. (2007). Employing the HPT process model to solve some problems of an English-medium instruction. Journal of Educational Technology, 23(3), 31-57.

Kirkpatrick, A. (2012). English in ASEAN: Implications for regional multilingualism. Journal of Multilingual and Multicultural Development, 33(4), 331-344.

Kirkpatrick, A. (2011). English as a medium of instruction in Asian education (from primary to tertiary): Implications for local languages and local scholarship. In L. Wei (ed.), Applied linguistics review 2, 2011 (pp.99-120). Berlin, Germany: De Gruyter Mouton.

Larsen-Freeman, D. (2016). Shifting metaphors: From computer input to ecological affordances to adaptation. Plenary presentation, International IATEFL Conference, Birmingham, UK, April, 2016.

Lee, Y. S. (2015). Innovating secondary English education in Korea. In B. Spolsky \& K. Sung (eds.), Secondary school English education in Asia (pp. 4764). New York: Routledge.

Lei, J., \& Hu, G. (2014). Is English-medium instruction effective in improving Chinese undergraduate students' English competence? IRAL, 52(2), 99-126.

Li, D. (1998). 'It's always more difficult than you plan and imagine': Teachers' perceived difficulties in introducing the communicative approach in South Korea. TESOL Quarterly 32 (4), 677-703.

Littlewood, W. (2007). Communicative and taskbased language teaching in East Asian classrooms. Language Teaching, 40, 243-249.

Macaro, E. (2009). Teacher use of code switching in the L2 classroom: Exploring 'optimal' use. In M. Turnbull \& J. Dailey-O’Cain (Eds.), First language use in second and foreign language learning (pp. 35- 49). Bristol, UK: Multilingual Matters.

Macaro, E. (2014). Overview: Where should we be going with classroom code-switching research? In R. Barnard \& J. McLellan (Eds.), Codeswitching in university English-medium classes: Asian perspectives (pp. 1023). Bristol, UK: Multilingual Matters.

Negishi, M., \& Tono, Y. (2014). An update on the CEFR-J project and its impact on English language education in Japan. Paper presented at the $5^{\text {th }}$ International Conference of the Association of Language Testers in Europe (ALTE), Paris, France, April 10-11.

Nishino, T. \& M. Watanabe (2008). Classroom-oriented policies versus classroom realities in Japan. TESOL Quarterly 42 (1), 133-138.

Norton, B. (2017). Identity and English language learners across global sites. In L. L. C. Wong \& K. Hyland (Eds.), Faces of English education:
Students, teachers, and pedagogy (pp.13-27). New York: Routledge.

Nunan, D. (2003). The impact of English as a global language on educational policies and practices in AsiaPacific region. TESOL Quarterly, 37(4),589-613.

Omar, A. H. (2012). Pragmatics of maintaining English in Malaysia's education system. In E. Low \& A. Hashim (eds.), English in Southeast Asia: Features, policy and language in use (pp. 155-174). Amsterdam, The NetherlandsL John Benjamins Publishing Co.

Phyak,P.B. (2011). Beyond the façade of language planning for Nepalese primary education: Monolingual hangover, eliticism, and displacement of local languages. Current Issues in Language Planning, 12(2), 265-287.

Read, J. (2014).The influence of the common European framework of reference (CEFR) in the Asia-Pacific region. Language Education and Acquisition Research Network (LEARN) Journal (Special Issue), 33-39.

Sato, K. \& R. C. Kleinsasser (1999). Communicative language teaching (CLT): Practical understandings. Modern Language Journal, 83 (4), 494-517.

Shohamy, E. (2013) A critical perspective on the use of English as a medium of instruction at universities. In A. Doiz, D. Lasagabaster, \& J. M. Siera (Eds.) English-medium instruction at universities: Global challenges (pp. 196-210). Bristol, England: Multilingual Matters.

Stevick, E. (1980). Teaching languages: A way and ways. Rowley, MA: Newbury House.

Taguchi, N., \& Naganuma, N. (2006). Transition from learning English to learning in English: Students' perceived adjustment difficulties in an English-medium university in Japan. Asian EFL Journal 8(4), 52-73.

Wang, Q. (2007). The National Curriculum changes and their effects on English language teaching in the People's Republic of China. In J. Cummins \& C. Davison (Eds.), International handbook of English language teaching (pp. 87-105). Boston, MA: Springer Science \& Business Media. Online access via SpringerLink.

Walker, S., \& Decker, D. (2008). The Lubuagan mother tongue education experiment (FLC): A report of comparative test results. Manila: Summer Institute of Linguistics International.

Wu, J. (2012). Policy perspectives from Taiwan. In M. Byram \& L. Pamenter (Eds.),The Common European framework of reference: The globalization of language education policy (pp. 213-223). Bristol, UK: Multilingual Matters. 


\title{
WHAT CAN THE NATIONAL FOREIGN LANGUAGE PROJECT 2020 LEARN FROM ASIAN EXPERIENCES?
}

\author{
Le Van Canh ${ }^{1}$, Nguyen Thi Ngoc ${ }^{2}$ \\ ${ }^{I}$ Centre for Language Education Research and Quality Assurance, \\ VNU University of Languages and International Studies, Pham Van Dong, Cau Giay, Hanoi, \\ Vietnam \\ ${ }^{2} N g h e$ An College of Education, Le Viet Thuat, Vinh, Nghe An, Vietnam
}

\begin{abstract}
The National Foreign Language Project 2020 has entered the $6^{\text {th }}$ year of its life (2008-2017), and throughout its short life, controversies and doubts have been cast over its practicality from both the domestic and international professional discourses as well as from home mass media. In an attempt to offer some advice to the Ministry of Education and Training on the needed strategic adjustments for the remaining time of the Project, this paper analyzes the status quo of recent English language initiatives in some Asian countries. The paper, then, presents the recommendations for the locus of change that the Project needs to target at in its remaining timelife.
\end{abstract}

Keywords: National Foreign Language Project 2020, experiences, Asian countries 